\title{
Fine-Scale Monitoring of Routine Deep Dives by Gravid Leatherback Turtles during the Internesting Interval Indicate a Capital Breeding Strategy
}

\author{
Junichi Okuyama ${ }^{1,2}$, Jeffrey A. Seminoff ${ }^{1}$, Peter H. Dutton ${ }^{1}$ and Scott R. Benson ${ }^{3 *}$ \\ ${ }^{1}$ Marine Mammal and Turtle Division, Southwest Fisheries Science Center, National Marine Fisheries Service, National \\ Oceanic and Atmospheric Administration, La Jolla, CA, USA, ${ }^{2}$ Research Center for Subtropical Fisheries, Seikai National \\ Fisheries Research Institute, Fisheries Research Agency, Ishigaki, Japan, ${ }^{3}$ Marine Mammal and Turtle Division, Southwest \\ Fisheries Science Center, National Marine Fisheries Service, National Oceanic and Atmospheric Administration, Moss \\ Landing, CA, USA
}

OPEN ACCESS

Edited by:

Rob Harcourt,

Macquarie University, Australia

Reviewed by:

Richard Reina,

Monash University, Australia

Gail Schofield,

Deakin University, Australia

*Correspondence:

Scott R. Benson

scott.benson@noaa.gov

Specialty section: This article was submitted to

Marine Megafauna,

a section of the journal

Frontiers in Marine Science

Received: 31 July 2016 Accepted: 30 August 2016 Published: 13 September 2016

Citation:

Okuyama J, Seminoff JA, Dutton PH and Benson SR (2016) Fine-Scale Monitoring of Routine Deep Dives by Gravid Leatherback Turtles during the Internesting Interval Indicate a Capital

Breeding Strategy.

Front. Mar. Sci. 3:166

doi: 10.3389/fmars.2016.00166
The dive behavior of gravid leatherback turtles (Dermochelys coriacea) was studied during the internesting interval in two western Pacific nesting regions: Papua Barat, Indonesia, and the Solomon Islands in 2006, 2007, and 2010. We used three types of dive data: time-at-depth data (Papua Barat: $N=4$; Solomon Islands: $N=6$ ), intermittent dive data (Papua Barat: $N=6$ ) obtained from ARGOS satellite transmitters, and continuous dive data obtained from recovered semi-archival tags (Papua Barat: $N=1$, Solomon Islands: $N=1$ ). All dive data demonstrated that the leatherback turtles routinely dove to deep waters (around $150 \mathrm{~m}$ ) throughout the internesting interval. The continuous dive data showed that turtles spent $37.3 \%$ of their time in routine deep dives and that they stayed in cold waters below the thermocline. Fine-scale monitoring (1-s interval, $0.5 \mathrm{~m}$ of resolution) suggested that these routine deep dives were not accompanied with any wiggles (up-and-down undulations in the depth profile) or flat-bottom phases, and they reached deep waters by gliding, which suggests that these dives may have served to conserve energy and/or to thermoregulate. Comparison with the dive behavior in other regions (Costa Rica, French Guiana, Grenada, Malaysia, and St. Croix) suggests that gravid leatherback turtles in all regions except French Guiana assume an energy-saving strategy during the internesting interval that involves gliding to or resting on the sea floor in colder water. The behavioral tactics (dive patterns) they use, however, differ because of bathymetric constraints.

Keywords: Dermochelys coriacea, dive classification, energy-saving, gigantothermy, reproductive strategy, supervised machine-learning, thermoregulation

\section{INTRODUCTION}

Reproductive performance is affected ecologically and physiologically by physical environmental factors. Across a variety of taxa, variation in environmental characteristics such as food availability or climate conditions can have dramatic repercussions on reproductive traits such as clutch size or reproductive frequency (e.g., Seigel and Fitch, 1985; Lourdais et al., 2002; Wallace et al., 2007). 
To cope with limiting and/or fluctuating food resources, for example, organisms have evolved a wide range of behavioral strategies to acquire energy and allocate this to reproduction. One fundamental dichotomy in reproductive behavior is between species that fuel reproduction with recently acquired energy ("income breeders") and those that rely on stored energy reserves (“capital breeders," Drent and Daan, 1980). Theoretical and empirical studies on the evolution of capital vs. income breeding should take into account the important roles played by thermoregulatory and metabolic systems (Bonnet et al., 1998). Therefore, ectotherms typify capital breeders because the energetic costs associated with storage, maintenance, and use of body reserves prior to reproduction are lower (Bonnet et al., 1998).

Sea turtles are marine ectotherms, although larger turtles such as leatherback, Dermochelys coriacea and loggerhead turtles, Caretta caretta have the ability to maintain body temperature greater than their environment (Bostrom et al., 2010; Sato, 2014). They are commonly considered to be capital breeders because the females are thought to cease feeding and rely entirely on energy reserves during the reproductive season (Miller, 1997). Nevertheless, feeding during the reproductive season has been suggested in green turtles, Chelonia mydas (Hochscheid et al., 1999; Hays et al., 2002), hawksbill turtles, Eretmochelys imbricata (Santos et al., 2010), loggerhead turtles (Schofield et al., 2006), and leatherback turtles (Southwood et al., 2005; Fossette et al., 2008b; Casey et al., 2010). Reproduction in sea turtles is energetically costly because adult females come ashore regularly throughout the nesting season (which lasts multiple months) to lay successive clutches of several dozen eggs. Therefore, sea turtles should conserve their energy during the period between nesting events (the internesting interval) to enhance their seasonal reproductive success (Wallace et al., 2005). To meet the energetic demand for reproduction during the internesting interval, sea turtles use behavioral strategies that limit unnecessary energy expenditure such as resting on the sea floor (e.g., Hochscheid et al., 1999) or in the water column at the depth of neutral buoyancy (e.g., Minamikawa et al., 1997). On a similar note, loggerhead turtles adjust their behavior depending on environmental conditions to accelerate egg maturation and thus maximize reproductive output: they increase their activity level in cold water and rest in warm water (Fossette et al., 2012).

Leatherback turtles exhibit the highest reproductive effort of all sea turtles (Miller, 1997). During the internesting interval, gravid leatherbacks undertake three major types of dive patterns. The first type is characterized by the flat-bottomed dives (U-dives) made by turtles to lie on the sea floor at relatively shallow depths (Malaysia; Eckert et al., 1996, Costa Rica; Southwood et al., 1999, 2005; Reina et al., 2005; Wallace et al., 2005; Shillinger et al., 2010). The second type comprises routine dives to deep waters that are made throughout the internesting interval (St. Croix; Eckert et al., 1986, 1989, Grenada; Myers et al., 2006; Myers and Hays, 2006). The last type is also characterized by continuous dives, but to shallow waters (Fossette et al., 2007). Therefore, the common assumption is that gravid leatherback turtles exhibit several behavioral strategies during the internesting interval (Fossette et al., 2007, 2008b): the
"Pacific strategy," whereby swimming activity is reduced to limit energy expenditure between two consecutive oviposition events (Eckert et al., 1996; Reina et al., 2005; Southwood et al., 2005; Wallace et al., 2005); and the "Atlantic strategy," whereby diving and swimming continue throughout the internesting interval, probably for feeding at the deep-scattering layer (DSL) (Eckert et al., 1989) or in shallow waters (Fossette et al., 2008b). This hypothesis predicts that gravid leatherback turtles adjust their reproductive behavior (e.g., capital or income) according to the characteristics of their environment (geographical features). However, a recent study investigating gastrointestinal tract temperatures at St. Croix observed sporadic feeding associated with routine deep dives; yet this occurred mainly in the first 4 days of the internesting interval (Casey et al., 2010); the authors concluded that gravid leatherbacks are opportunistic feeders. Similarly, in French Guiana beak-movement events in turtles performing continuous shallow dives were observed mainly in the first 2 days (Fossette et al., 2008b). In addition, morphological and physiological assessments in French Guiana supported the notion that turtles do not actively feed (Plot et al., 2013). Therefore, it is necessary to examine whether the bathymetric characteristics of the waters adjacent to nesting sites influence the behavioral strategy of leatherback turtles (capital or income) during the internesting interval.

Here, we report on the fine-scale dive behavior of gravid leatherback turtles during the internesting interval in the western Pacific, where the bathymetry exhibits drastic descents to depths $>1000 \mathrm{~m}$ within close distance (ca. $10 \mathrm{~km}$ ) to shore. Under these conditions, gravid leatherbacks are expected to dive to deeper waters. The objective of this study was to determine the dive patterns of gravid leatherback turtles during the internesting interval in the western Pacific, and to investigate how leatherbacks adjust their behavioral strategy to local bathymetry by comparing dive performance across nesting regions.

\section{MATERIALS AND METHODS}

The Indonesian Institute of Sciences (LIPI), and the Solomon Islands Department of Environment and Conservation provided research permits for telemetry deployments for this endangered species to aid in research and recovery.

\section{Field Methods}

Telemetry deployments were conducted at two major nesting beaches located on the northern Bird's Head coast in Papua Barat Indonesia (Jamursba-Medi and Wermon; Hitipeuw et al., 2007), and three beaches in the Solomon Islands (Litoghahira and Sasakolo, Santa Isabel Island) in 2006, 2007, and 2010 (See Benson et al., 2011). The bathymetries of the waters adjacent to these regions exhibit drop-offs to $>1000 \mathrm{~m}$ in depth (Figure 1). Of those tag data, we gathered dive data during the internesting interval from two different satellite-linked, platform transmitter terminal (PTT) transmitter models: the MK10 ( $n=10$; Wildlife Computers, Washington, USA) and the Satellite Relay Data Logger (SRDL; $n=6$; SMRU Instrumentation, St Andrews, U.K.; Table S1). Two PTTs (16263a and 16263b) were retrieved after tracking. These provided archival data of dive depth (1-s interval, 


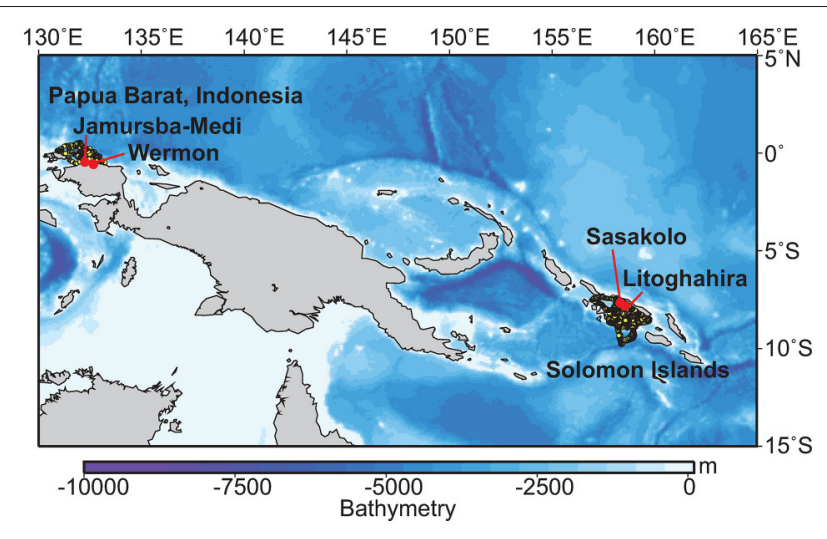

FIGURE 1 | A map showing the nesting beaches where the tags were deployed in the western Pacific and adjacent bathymetry. Yellow circles represent the horizontal movements of gravid leatherback turtles during internesting interval in two western Pacific nesting regions: Papua Barat, Indonesia $(N=10)$, and the Solomon Islands $(N=6)$ determined by satellite telemetry.

$0.5 \mathrm{~m}$ resolution), temperature ( $10 \mathrm{~s}$ interval, $0.05^{\circ} \mathrm{C}$ resolution), and relative light level (range: 25-225 units, corresponding to $10^{-1}-10^{-11} \mathrm{~W} \mathrm{~cm}{ }^{-2}$ at $550 \mathrm{~nm}, 1-$ min interval, 0.05 units resolution). In 2006 and 2007, we attached PTTs to the turtles with the aid of a flexible harness that consisted of soft nylon webbing and flexible polyvinyl tubing to cover the shoulder straps. The harness was held in place by a corrodible pin designed to release the harness in 18-24 months. For details of PTT attachment, see Benson et al. (2011). In 2010, the PTT was attached with a direct attachment approach (see Fossette et al., 2008a).

Internesting events were determined by the retrieved depth profile recorded in archival data, location data from Fastloc GPS, or haul-out data from the SRDL. The duration between nesting events was defined as the internesting interval. The transition distance between nesting locations on a given beach was calculated from the Fastloc GPS data.

\section{Analysis and Dive Classification of Archival Data}

The fine-scale archival data were analyzed using IGOR Pro ver. 6.3 (WaveMatrics, Inc., Lake Oswego, OR, USA). Dive parameters were extracted for each dive. A dive was defined as any dive that exceeded $1 \mathrm{~m}$ in depth and $10 \mathrm{~s}$ in duration. The remaining time was defined as surface period.

To understand the fine-scale dive data, we visually assessed the dive profiles made during the internesting interval and then classified these into four types: DC1, skewed-right deep dives; DC2, skewed-left dives; DC3, shallow dives; and DC4, extra deep dives (Figure 2A). Because we obtained a large amount of dive data, we used a decision tree to automatically classify dive types using supervised machine-learning. We used the C4.5 algorithm (Quinlan, 1993) implemented in Weka v3.6.12 (Hall et al., 2009). Twenty-five parameters for each dive were calculated: maximum depth $(\mathrm{m})$, duration $(\mathrm{min})$, descent rate $\left(\mathrm{m} \mathrm{s}^{-1}\right)$, ascent rate $(\mathrm{m}$ $s^{-1}$ ), skewness, and $D_{1-20}: 20$ depth profiles for each dive by dividing dive duration into 20 equal parts and computing the proportion of each corresponding depth to the total depth of the dive, thereby standardizing for varying depth. Descent rate was calculated from the beginning of a dive to its maximum depth, while ascent rate was calculated from the maximum depth to the end of a dive. Additionally, the descent rate during the first one-third and last two-thirds of the descent were calculated to determine whether the turtles glided, although these parameters were not included as a parameter for dive classification. The skewness of a dive profile was calculated as the ratio of the time at the maximum depth to dive duration (0-1). In total, we obtained data for 12,853 dives made during five internesting intervals by two turtles (see Section Results). We created a training dataset with data for a subset of 1000 dives, which was used for model development to predict the dive types (DC1DC4). Dives included in the training dataset were randomly selected and the number was determined to obtain $>95 \%$ correct classification.

We used a chi-square test and a post-hoc residual analysis to determine whether each dive type followed a specific dive type in two consecutive dives. For this statistical test, DC4 was removed because its expected values were less than five (Cochran's rule, Cochran, 1954).

In the fine-scale dive profiles extracted from archival data, we observed that the turtles stayed at the surface for extended periods (see Section Results). To extract the extended surface period (ESP), we calculated the outliers of the residuals from a linear regression between post-dive surface duration (PDSD) and dive duration using the Smirnov-Grubbs test. We based this on previous reports indicating a linear relationship between PDSD and dive duration in leatherback turtles (Wallace et al., 2005; Fossette et al., 2007).

Because the duration of internesting intervals varied across events and turtles, the time-series shift in dive characteristics was compared among the period from the first day to last day of the internesting interval which was shortest in each measurement method/nesting region.

\section{Analysis of ARGOS Satellite-Linked Transmitter Data}

Time-at-depth (TAD) data were recorded by MK10s (Wildlife Computers) on 10 turtles (Table S1). TAD data were summarized as a time-at-depth distribution based on the time spent in each of 12 depth bins. The upper limits of the depth bins (in meters) were: $5,15,25,35,50,75,100,150,200,300,500$, and $>500$. Temperature was recorded as time-at-temperature (TAT). Like TAD data, TAT data were summarized as a time-at-temperature distribution based on the time spent in each of 14 temperature bins. The upper ranges of the temperature bins (in degrees Celsius) were: $4,8,10,12,14,16,18,20,22,24,26,28,32$, and $>32$. TAD and TAT data were aggregated over four 6 -h periods prior to transmission to Argos receivers. The 6-h periods were programmed at the Universal Time, Coordinated (UTC), and thus correspond to local time at Papua Barat as 03:00-09:00, 09:00-15:00, 15:00-21:00, and 21:00-03:00 h, and at Solomon Islands as 05:00-11:00, 11:00-17:00, 17:00-23:00, and 23:0005:00 $\mathrm{h}$. These time periods reflected dawn, mid-day, dusk, and 

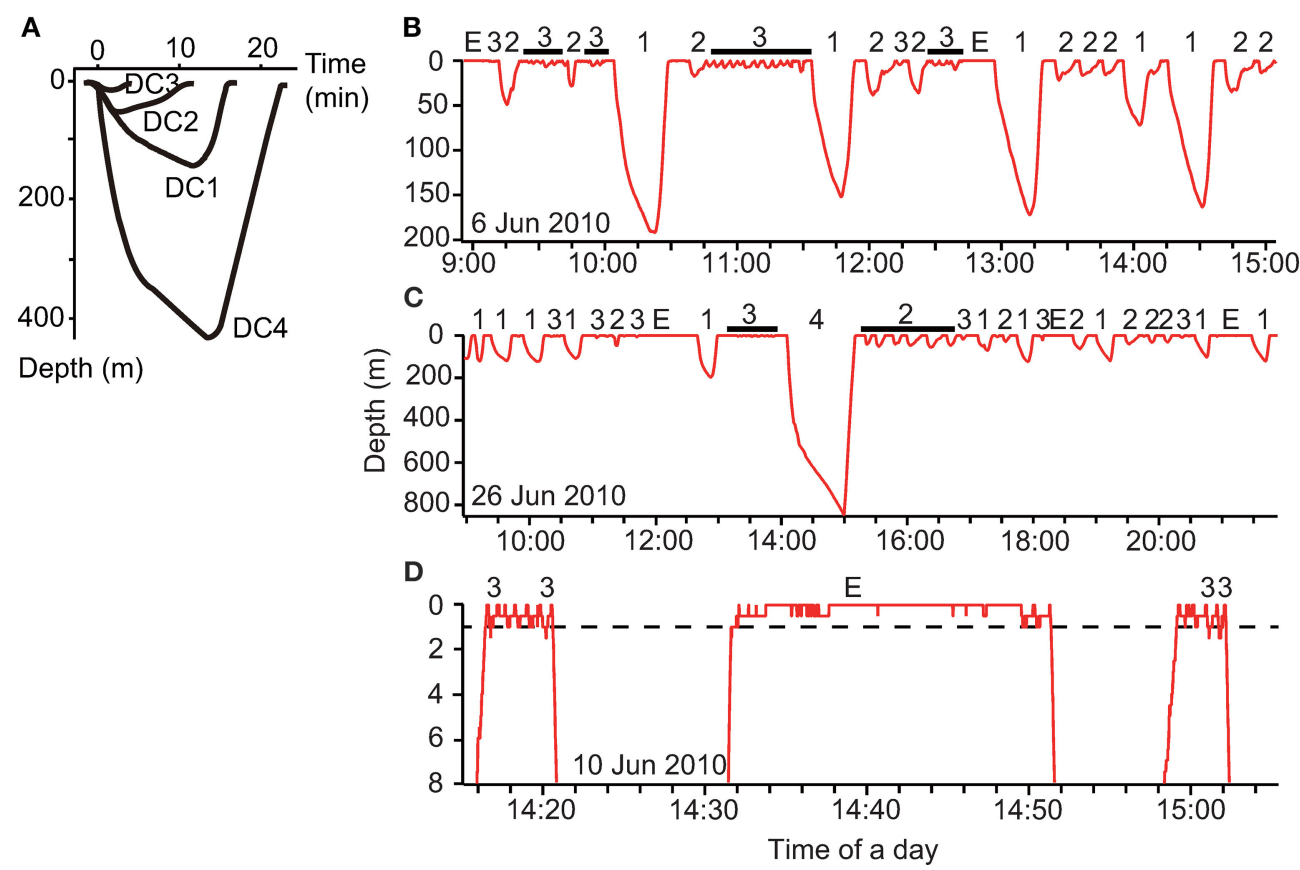

FIGURE 2 | (A) Schematic representation of the four dive types made by gravid leatherback turtles during the internesting interval. Typical dive profiles from archived, continuous data within three depth ranges: (B) 0-200, (C) 0-850, and (D) 0-8 m. The numbers above the profiles indicate the dive types (DC1-DC4), while E represents the extended surface period (ESP).

midnight periods in each location. Note there was a 2 -h difference between each location.

SRDLs recorded data from six turtles (Table S1). Owing to the limited bandwidth of the Argos system, depth was relayed with an accuracy of $\pm 2 \mathrm{~m}$ for dives to $65 \mathrm{~m}, \pm 4 \mathrm{~m}$ for dives between 65 and $128 \mathrm{~m}$, and approximately $\pm 30 \mathrm{~m}$ for dives $>500 \mathrm{~m}$ (for details see Myers and Hays, 2006). Using bespoke software, depth data were analyzed onboard the SRDL prior to transmission. Data for individual dives were generated when the depth exceeded $10 \mathrm{~m}$. Once a dive was completed, onboard software examined the dive profile and determined the time and depth of the five most prominent points of inflection during the dive. The time and depth of these five points, together with the time of the end of the dive and the dive's duration, were then transmitted. For temperature data, 12 depth-temperature points were obtained for each dive profile. A detailed description of how SRDLs measure water temperature is given in McMahon et al. (2005). In conjunction with data for individual dives, a summary of all dive information in 6-h periods was also generated by each SRDL. Each summary period included data on the percentage of time spent below $10 \mathrm{~m}$ and the mean depth of dives that exceeded $10 \mathrm{~m}$.

\section{RESULTS}

\section{Internesting Events}

In total, data from dives by 16 turtles were recorded during 65 internesting intervals (Table S1). The average duration of the internesting interval was $9.4 \pm 1.7 \mathrm{~d}(N=39)$ in Papua
Barat and $10.9 \pm 4.4 \mathrm{~d}(N=26)$ in Solomon Islands (Table S1). These were significantly different (Mann-Whitney test, $U=269$, $P<0.01)$. All consecutive nesting events in Papua Barat occurred in close proximity $(N=20,5.1 \pm 6.4 \mathrm{~km}$, $\min -\max : 0.17-$ $26.2 \mathrm{~km}$ ). In Solomon Islands, all turtles except ID17712 nested on beaches around Litoghahira, and Sasakolo on Santa Isabel Island, where we deployed the PTTs. ID17712, however, moved to the Malaita Islands for her second tracked nesting event. The average transition distance between consecutive nesting locations in Solomon Islands was $14.0 \pm 55.9 \mathrm{~km}(N=25$, min-max: $0.07-$ $281.3 \mathrm{~km}$ ), which was significantly farther than in Papua Barat (Mann-Whitney test, $U=148, P<0.01$ ). Overall, $82.2 \%$ of all nesting events occurred within $5 \mathrm{~km}$ of each other.

\section{Dive Performance}

Fine-scale dive data were recorded from 8259 and 8093 dives by turtles nesting in Papua Barat and Solomon Islands, respectively. Moreover, data from 3870 dives including 579 sets of summary data were obtained from six turtles deployed with an SRDL. The dive profiles collected from SRDLs were intermittent because they were transmitted via ARGOS satellites (Figure S1). The MK10s provided 501 TAD recordings (made over $6-\mathrm{h}$ periods) from four turtles nesting in Papua Barat and 552 TAD recordings from six turtles in Solomon Islands.

The gravid leatherback turtles used a wide vertical range of water adjacent to nesting beaches during the internesting interval, to depths of $846 \mathrm{~m}$ in Papua Barat and $485.5 \mathrm{~m}$ in Solomon Islands (Figure 2, Figure S1). However, such extradeep dives approaching these depths occurred very infrequently. 
According to archival data, the turtles in Papua Barat dove to $20.1 \pm 43.0 \mathrm{~m}$ for $4.0 \pm 6.0 \mathrm{~min}$ (mean \pm standard deviation), while in Solomon Islands they dove to $25.2 \pm 50.3 \mathrm{~m}$ for $3.9 \pm$ $6.6 \mathrm{~min}$. The TAD data showed that the modal bin of maximum depth in a 6-h period fell within 150-200 $\mathrm{m}$ for almost all turtles in both nesting regions (Figure S1). There was no significant difference in the proportions of TAD in each depth bin between Papua Barat $(N=4)$ and Solomon Islands $(N=6)$ (Chi-square test, $\left.f=4, X^{2}=0.66, P=0.96\right)$. The SRDL data showed that the turtles nesting in Papua Barat dove to $68.5 \pm 62.4 \mathrm{~m}$ for $14.1 \pm$ 6.3 min (mean \pm standard deviation; Figure S1). This difference in the dive parameters as estimated from archival and SRDL data was a product of the difference in the dive definition. If dives shallower than $10 \mathrm{~m}$ were excluded, the archival data were similar to the SRDL data, with average dive depths of $60.4 \pm 62.8$ and $92.2 \pm 60.2 \mathrm{~m}$. This indicates that dives shallower than $10 \mathrm{~m}$ made up a considerable proportion of all dives. Summary statistics from the SRDL data showed that the proportion of the internesting interval spent diving was $68.0 \pm 5.2 \%$.

Dive duration was significantly related to dive depth $\left[F_{(1,20,221)}=62,536, \quad P<0.0001\right.$, Figure 3A $]$. Gravid leatherbacks experienced a wide range of water temperatures. The mean water temperature was $28.8 \pm 3.5^{\circ} \mathrm{C}$ at the sea surface, but decreased dramatically with depth, to $5.4^{\circ} \mathrm{C}$ at $846 \mathrm{~m}$ (Figure 3B). The thermocline occurred around $100-150 \mathrm{~m}$ (Figure 3B).
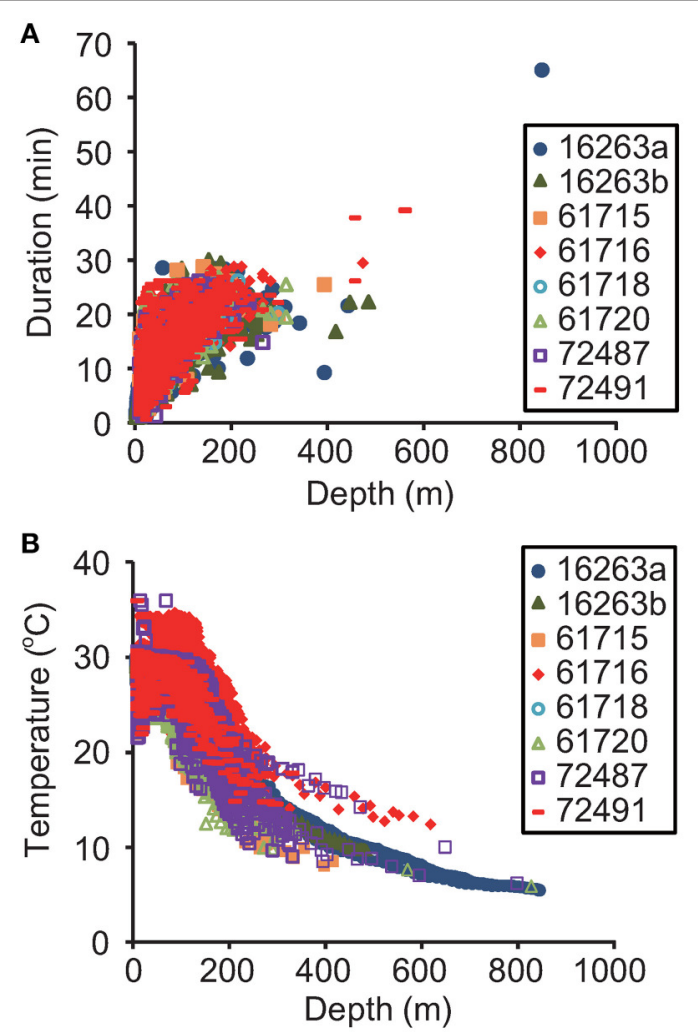

FIGURE 3 | Relationships (A) between maximum dive depth and dive duration and $(B)$ between depth and temperature obtained from archived $(N=2)$ and SRDL data $(N=6)$.
The mean duration of the PDSD was $1.4 \pm 3.3 \mathrm{~min}$ and $1.2 \pm 2.4 \mathrm{~min}$ in Papua Barat and Solomon Islands, respectively. The PDSD had a significant relationship with dive duration $\left[F_{(1,16,351)}=2763, P<0.0001\right.$, Figure 4A $]$. At the surface, the ambient temperature often increased appreciably (Figure 4B). There were 470 significant outliers in a regression analysis ( $P<0.05$, Smirnov-Grubbs test). Of these outliers, only one PDSD was significantly shorter than expected relative to dive duration, while in the remaining 469 cases the turtles stayed at the surface longer (up to $67.6 \mathrm{~min}$ ). These significantly longer surface periods were defined as ESPs (Figure 2D).

\section{Dive Classification and Performance}

Archival data showed that gravid leatherback turtles performed several types of dives (Figure 2). The C4.5 algorithm correctly classified $97.7 \%$ (of 1000) of the training dataset. The correct classification rates for each dive class were DC1: $98.6 \%(N=283)$, DC2: $92.8 \%(N=195)$, DC3: $99.0 \%(N=517)$, and DC4: $100.0 \%$ $(N=5)$. After training, the $\mathrm{C} 4.5$ algorithm predicted the dive types of complete dives (Table 1). Characteristics of each dive type and ESPs are summarized in Table 1. The proportions of the internesting interval spent in each type of dive or at the surface were $37.3,19.9,17.5,0.3,17.8$ and 7.2\% for DC1, DC2, DC3, DC4,
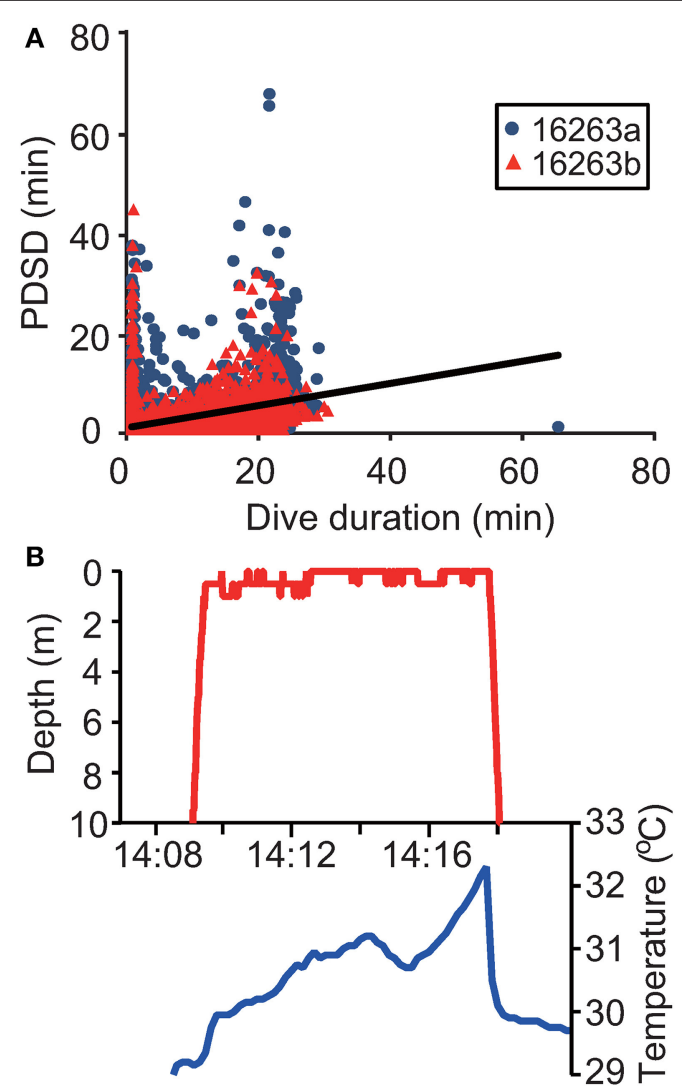

FIGURE 4 | (A) Relationship between dive duration and post-dive surface duration (PDSD) in two gravid leatherback turtles. The solid line represents the linear regression ( $N=6268, y=0.3 x+1.6)$. (B) Ambient temperatures while a turtle stayed at the surface. 
TABLE 1 | Characteristics of each behavioral category.

\begin{tabular}{|c|c|c|c|c|c|c|c|c|c|}
\hline $\begin{array}{l}\text { Behavior } \\
\text { type }\end{array}$ & $N$ & $\begin{array}{c}\text { Max. } \\
\text { Depth (m) }\end{array}$ & $\begin{array}{l}\text { Duration } \\
\text { (min) }\end{array}$ & $\begin{array}{l}\text { PDSD } \\
\text { (min) }\end{array}$ & $\begin{array}{l}\text { Descent } \\
\text { rate }(\mathrm{m} / \mathrm{s})\end{array}$ & $\begin{array}{l}\text { First one-third } \\
\text { descent }(\mathrm{m} / \mathrm{s})\end{array}$ & $\begin{array}{l}\text { Last two-thirds } \\
\text { descent (m/s) }\end{array}$ & $\begin{array}{c}\text { Ascent } \\
\text { rate }(\mathrm{m} / \mathrm{s})\end{array}$ & $\begin{array}{c}\text { Time } \\
\text { spent (\%) }\end{array}$ \\
\hline DC1 & 1633 & $141.3 \pm 44.8$ & $18.2 \pm 4.2$ & $4.5 \pm 5.3$ & $0.24 \pm 0.09$ & $0.38 \pm 0.12$ & $0.16 \pm 0.12$ & $0.52 \pm 0.20$ & 37.3 \\
\hline DC2 & 1362 & $50.1 \pm 22.5$ & $11.6 \pm 4.2$ & $2.1 \pm 2.1$ & $0.26 \pm 0.10$ & $0.40 \pm 0.08$ & $0.20 \pm 0.17$ & $0.18 \pm 0.10$ & 19.9 \\
\hline DC3 & 13,348 & $4.5 \pm 5.7$ & $1.2 \pm 1.6$ & $0.8 \pm 1.9$ & $0.09 \pm 0.11$ & $0.13 \pm 0.14$ & $0.02 \pm 0.07$ & $0.11 \pm 0.08$ & 17.5 \\
\hline DC4 & 9 & $441.8 \pm 165.1$ & $24.0 \pm 16.0$ & $8.2 \pm 8.1$ & $0.75 \pm 0.41$ & $0.91 \pm 0.24$ & $0.28 \pm 0.67$ & $0.99 \pm 0.29$ & 0.3 \\
\hline Surface & 15,877 & & $1.0 \pm 1.3$ & & & & & & 17.8 \\
\hline ESP & 469 & & $13.1 \pm 8.1$ & & & & & & 7.2 \\
\hline
\end{tabular}

surface, and ESP, respectively (Table 1). The ratio of DC3 dives shallower than $2 \mathrm{~m}$ relative to all other dive types was $43.6 \%$ in Papua Barat and $66.0 \%$ in Solomon Islands.

The state transition between dive types in two consecutive dives was varied significantly (Chi-square test, $f=6, X^{2}=56.7$, $P<0.001$, Table 2). Post-hoc residual analysis indicated that DC1 dives were followed by DC2 dives more often than expected $(P<0.01)$ and by DC3 dives less often than expected $(P<0.05)$. DC2 dives were usually followed by DC1 dives $(P<0.01)$, but not by DC3 dives $(P<0.01)$. DC3 dives were consistently followed by DC3 dives more often than expected $(P<0.01)$, and by DC1 and DC2 less often than expected. DC4 dives were usually followed by DC3 dives $(P<0.05)$. The duration of DC1 dives that were followed by DC2 dives was significantly longer than those followed by a DC1 dive $(t=9.9, P<0.001)$. Nevertheless, the time spent at the surface between a DC1 dive and a DC2 was not significantly different from that spent between consecutive DC1 dives $(t=0.56, P=0.57)$. The incidence of ESPs was greatest after long or short dives. Out of 469 ESPs, 39\% occurred after DC1 or DC4 dives and 23\% after DC3 dives following DC1 or DC4 dives. Another $17 \%$ occurred after $>3$ consecutive DC3 dives.

\section{Diel Pattern}

The maximum dive depth recorded in archival data varied significantly throughout the day (Kruskal-Wallis test, Papua Barat: $X^{2}=114.2, P<0.001$, Solomon Islands: $X^{2}=136.6$, $P<0.001$, Figure 5, Figure S2). The maximum depth attained was deeper during daytime, particularly early morning (06:0008:00), than at night. The proportion of time spent in each behavioral category (dive and surface) also changed throughout the day (Chi-square test, Papua Barat: $X^{2}=2268.8, P<0.001$, Solomon Islands: $X^{2}=2757.6, P<0.001$, Figure S3). The time spent in DC1 dives per hour increased during the day, notably in early morning (06:00-08:00). The time spent in DC2 dives increased at night, while more time was spent in DC3 dives and ESP during daytime hours. The time spent at surface did not vary. Extra-deep DC4 dives were only observed during daytime. The relative light level changed on a diel cycle and decreased with depth (Figure S2). The relative light level at maximum dive depth (around 150-200 m) during the daytime was higher than it was at the surface during the night. Daytime DC1 dive depth was weakly but significantly associated with the relative light level $\left[F_{(1,898)}=4.08, P<0.05\right]$. Most ESPs occurred during the day (Figure S3). ESPs tended to occur in succession when
TABLE 2 | State transitions between dive classes (DC) in consecutive dives.

\begin{tabular}{lcccc}
\hline Current dive & \multicolumn{4}{c}{ Next dive } \\
\cline { 2 - 5 } & DC1 & DC2 & DC3 & DC4 \\
\hline DC1 & 16.5 & $31.5^{++}$ & $51.9^{--}$ & 0.1 \\
DC2 & $29.3^{++}$ & 16.1 & $54.5^{--}$ & 0.0 \\
DC3 & $7.2^{--}$ & $4.6^{--}$ & $88.2^{++}$ & 0.0 \\
DC4 & 11.1 & 11.1 & $77.8^{+}$ & 0.0 \\
\hline
\end{tabular}

A positive symbol indicates that the current dive class was followed more often than expected by dives of the next class $\left({ }^{+} P<0.05,{ }^{++} P<0.01\right)$, while a negative symbol indicates the reverse. Note that DC4 was not included in residual analysis (see text).

observed. Most of the intervals between consecutive ESPs (78\%) were shorter than $3 \mathrm{~h}$.

The depth profiles from TAD data varied significantly across the four 6-h periods of the day (Chi-squares test, Papua Barat: $X^{2}=75.1, P<0.01$, Solomon Islands: $X^{2}=122.6, P<0.01$, Figures 5C,D). The turtles in both regions frequently dove to deeper waters $(>150 \mathrm{~m})$ from early morning to evening (03:0015:00 in Papua Barat; 05:00-17:00 in Solomon Islands), while they made shallow dives $(<150 \mathrm{~m})$ from evening to early morning (15:00-03:00 in Papua Barat; 17:00-5:00 in Solomon Islands). The SRDL and archival data showed significant variation in maximum dive depth by hour of the day (Kruskal-Wallis test, $X^{2}=103.4, P<0.001$, Figure 5E). The maximum of mean dive depth was observed in early morning (06:00-08:00).

\section{Time-Series Shifts throughout an Internesting Interval}

All turtles dove continuously throughout the internesting interval (Figure S1). Average daily dive depth did not change significantly over time in the archival data (Kruskal-Wallis test, Papua Barat, Day 1-Day 9: $X^{2}=14.1, P=0.08$; Solomon Islands, Day 1-Day $12: X^{2}=9.5, P=0.57$ ) or in the summary statistics from the SRDL data (Day 1-Day 9, Kruskal-Wallis test, $X^{2}=$ 7.6, $P=0.47)$. Similarly, TAD depth profiles did not change over time (Day 1-Day 10, Chi-square test, Papua Barat: $X^{2}=28.0$, $P=0.99$, Solomon Islands: $\left.X^{2}=7.2, P=1.00\right)$. However, the proportion of time spent in each behavioral category did change (Chi-square test, Papua Barat: $X^{2}=907.5, P<0.001$; Solomon Islands: $\left.X^{2}=1107.7, P<0.001\right)$. On Day 1 and Day 9, deeper DC1 and DC2 dives, were predominant, while in the middle of 

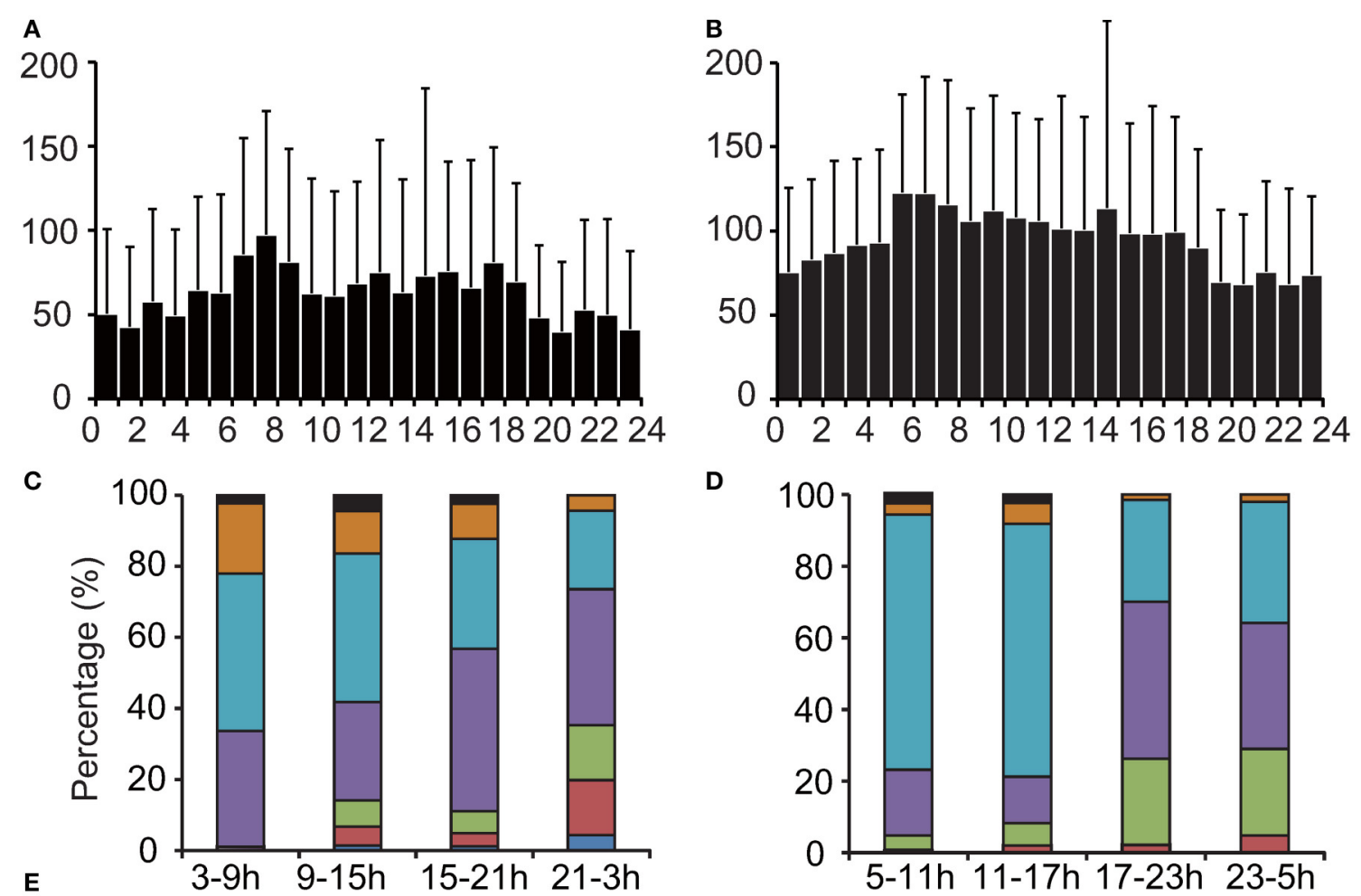

D
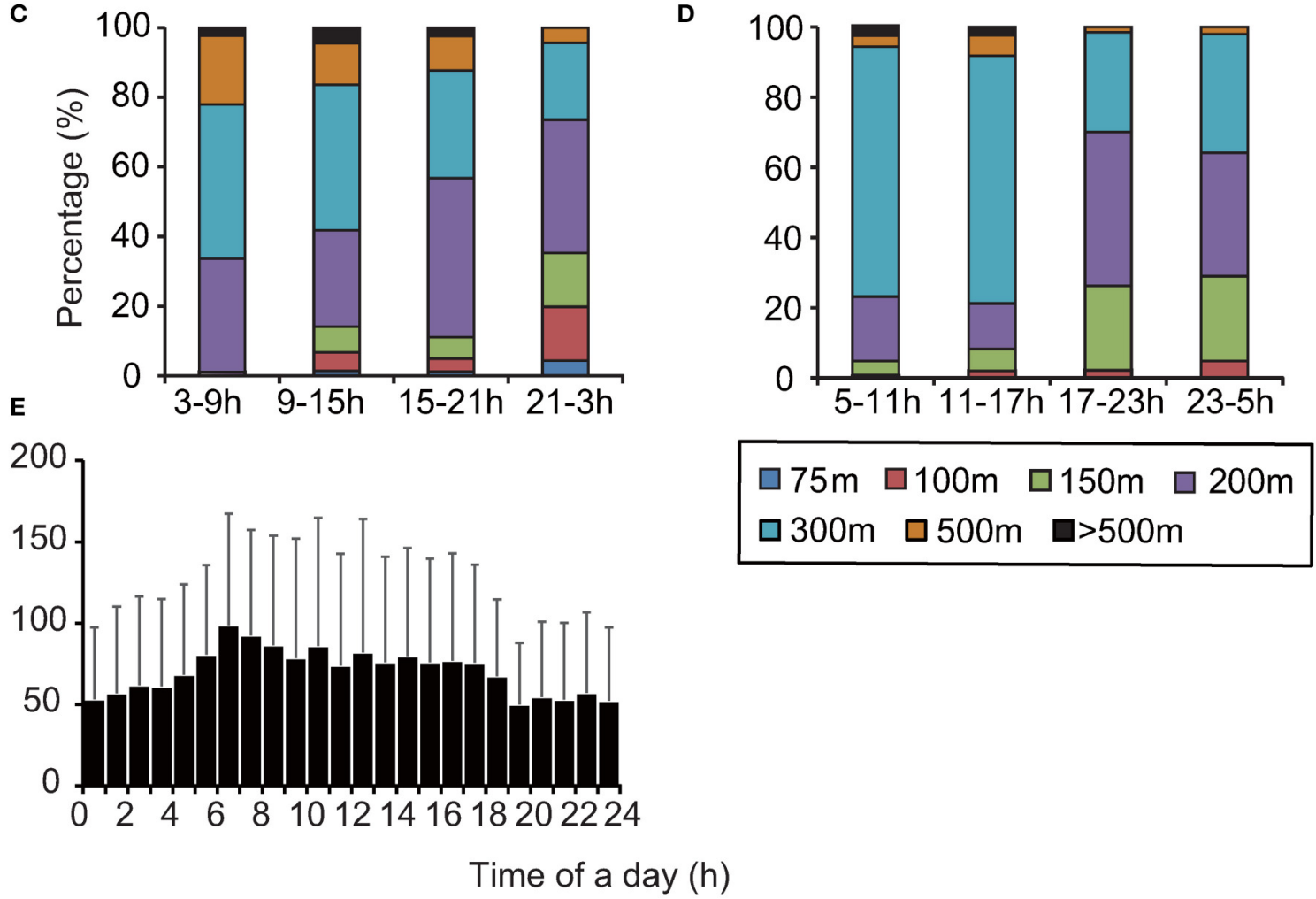

FIGURE 5 | Comparison maximum dive depth distributions among archived, SRDL, and TAD data from two nesting regions. (A) Archived data, Papua Barat, $N=1$, (B) archived data, Solomon Islands, $N=1$, (C) TAD data, Papua Barat, $N=4$, (D) TAD data, Solomon Islands, $N=6$, (E) SRDL data, Papua Barat, $N=6$. Note that the maximum dive depth recorded in TAD data was represented as a maximum depth bin for a 6-h period.

the internesting interval the proportion of time in ESP increased (Figure S4). Only one interval showed a typical diel pattern, remaining in shallower water at night, 2 days before nesting at Papua Barat (Figure S1).

\section{DISCUSSION}

Here, we present the dive performance of gravid leatherback turtles during the internesting interval in Papua Barat and Solomon Islands using three types of dive data: archival, TAD, and SRDL data. All of the data showed similar trends of dive performance in Papua Barat and Solomon Islands
(Figure 5, Figure S1), indicating that TAD and SRDL data, although coarse, can provide an accurate picture of dive characteristics when combined with some fine-scale archival data.

Supervised machine-learning enabled us to drastically shorten the amount of time required to analyze a large amount of sensor data. The high correct classification rate displayed by the C4.5 algorithm indicates that each dive type accurately characterizes dive behavior and that the four types of dives composed the majority of dives made during the internesting interval. This allowed us to understand the purpose of each dive and, consequently, what turtles were doing. 


\section{Function of Dives and Surface Time during the Internesting Interval}

To the best of our knowledge, this is the first report demonstrating that gravid leatherback turtles routinely dive to $>100 \mathrm{~m}$ during the internesting interval in the Pacific. This deep dive was possible due to the bathymetry of the waters around Papua Barat and Solomon Islands. It is interesting that the dive patterns observed during the internesting interval in Papua Barat and Solomon Islands closely resemble those of the Caribbean (St. Croix, US Virgin Islands; Eckert et al., 1986; Grenada; Myers et al., 2006; Myers and Hays, 2006), more so than other nesting regions of the Pacific that are geographically closer (Costa Rica; Southwood et al., 1999; Reina et al., 2005; Shillinger et al., 2010 and Malaysia; Eckert et al., 1996). In Costa Rica and Malaysia, the leatherbacks performed the U-dives, which was associated with shallow bathymetry due to extensive continental shelf. In fact, the turtles in our study never showed such square-shaped dives. Almost all dive profiles were V-shaped or round-bottomed with a clear linear relationship between dive depth and dive duration.

More than one-third of the internesting interval was spent in DC1 dives, characterized as deep dives to around $150 \mathrm{~m}$. A behavioral analysis of deep dives using accelerometers (Fossette et al., 2010) indicated that deep DC1-type dives began with stroking for the first third of the descent, followed by gliding and then active swimming during ascent. It should be noted that few of the $\mathrm{DC} 1$ dives were accompanied with wiggles (up-and-down undulations in the depth profile) or flat-bottom phases, despite the fact that dive depth was recorded at a fine scale (1-s interval and $0.5 \mathrm{~m}$ resolution). If the turtles did anything during the $\mathrm{DC1}$ dive, the depth profile should have shown deviations such as wiggles for foraging (Fossette et al., 2008b; Casey et al., 2010), and flat-bottom periods for resting on the sea floor (Reina et al., 2005). These points indicate that the turtles may just dive by gliding and then ascend with active swimming during DC1 dives. Why do they need to attain deep waters by gliding? If they wanted to rest to maximize energy allocation to reproduction, they should do so at the depth of neutral buoyancy where the cost of shuttling to the surface is low. One possible explanation is the hypothesis that turtles dive to deep waters to avoid overheating (Southwood et al., 2005; Wallace et al., 2005; Shillinger et al., 2010). Gravid leatherback turtles may elevate their body temperature beyond their thermal limit because of "gigantothermy" (Paladino et al., 1990; Bostrom et al., 2010). Therefore, they need to minimize metabolic heat production. Deep dives take the turtles to cold waters beyond the thermocline, which enhances the thermal gradient between the core body temperature and the ambient temperature and facilitates efficient heat loss. Moreover, the SSTs in Papua Barat and Solomon Islands that the turtles experienced in the present study were higher than in the other regions (Costa Rica; Southwood et al., 2005; Shillinger et al., 2010 and St. Croix; Casey et al., 2010), indicating that the body temperatures of turtles at the sea surface in the present study could have been around $29.6^{\circ}-35.8^{\circ} \mathrm{C}$. This is based on previous results documenting a thermal gradient of $1.8^{\circ}-4.3^{\circ} \mathrm{C}$ between the core body temperature and ambient temperature in internesting leatherback turtles that were assumed to have made suitable circulatory adjustments to cool down (Paladino et al., 1990;
Southwood et al., 2005; Casey et al., 2010). Therefore, the need to expose themselves to cooler temperatures in our study sites may be greater than that in other regions. In conclusion, the purpose of $\mathrm{DC} 1$ dives may be to conserve energy and cool down.

Alternatively, deep dives with a diel pattern have been considered to be foraging on vertically migrating prey associated with the deep scattering layer (Eckert et al., 1986, 1989). In fact, the feeding behavior of gravid leatherback turtles nesting at St. Croix was inferred from the temperature of the gastrointestinal tract during the internesting interval (Casey et al., 2010). The characteristics (shape and dive depth) of these "foraging" dives are very similar to those of DC1 dives in our study, suggesting that the turtles nesting in Papua Barat and Solomon Islands may also feed. However, Casey et al. (2010) concluded that feeding was an opportunistic behavior, and the low prey ingestion rates did not provide sufficient energy for successful reproduction. Therefore, ingestion of prey and/or seawater may serve as a means for cooling down, rather than for energy gain (Southwood et al., 2005; Casey et al., 2010). It is possible that routine deep dives serve as avoidance of encountering predators. However, it might be inefficient avoidance behavior, because the known predators, sharks (Keinath and Musick, 1993) or killer whales (Orcinus orca, Pittman and Dutton, 2004) can attain to the depth of routine deep dives (e.g., white shark; Carcharodon carcharias, Bonfil et al., 2005, killer whales; Miller et al., 2010) It is more likely that leatherbacks execute rapid and unusually deep dives as a "flight response" to an attack or threat by a predator (Dill, 1987) instead of routine dives as a predator avoidance strategy. We have observed such sudden deep dives in leatherbacks at foraging areas in the Northeast Pacific (Dutton and Benson, unpublished).

The aerobic dive limits (ADL) of gravid leatherback turtles are estimated to be approximately 33-67 min (Southwood et al., 1999; Hays et al., 2004; Wallace et al., 2005). The durations of $>10,000$ dives we recorded showed a noticeable ceiling at around 25-30 min, beyond which we recorded few dives. A shorter ADL duration is appropriate given that the SST in our study was comparatively high relative to previous studies. High water temperature elevates the metabolic rate and consequently decreases dive duration (Southwood et al., 2003). Therefore, almost all of the DC1 dives did not exceed the ADL. In terms of optimal diving theory (Kramer, 1988), opportunistic feeding in deep waters where travel costs are high seems to be unprofitable. If cooler waters are considered a resource for turtles, then long, deep dives (within the ADL) are a reasonable way to maximize the time spent in cooler waters. However, additional studies making novel recordings, such as video and acceleration with concurrent monitoring of gastrointestinal tract temperature, are needed to determine the exact role of routine deep dives.

Routine DC1 dives often occurred in tandem with DC2 dives. State transition analysis of consecutive dive types demonstrated positive linkages in the transitions from $\mathrm{DC} 1$ to $\mathrm{DC} 2$, and vice versa, while the linkages to DC3 were negative (occurred less often than expected). The DC1-DC2 sequence was also documented in St. Croix (Eckert, 2002) and Costa Rica (Wallace et al., 2005). The descent rate of the first third of DC2 dives was similar to that of DC1 dives, while the ascent rate was much slower than that of DC1 dives, indicating that the turtles swam 
by stroking during descent and slowly moved to the surface. The depth of DC2 dives was near the neutral buoyancy depth of nesting leatherback turtles with full lungs (Fossette et al., 2010), implying that the turtles may terminate gliding as they do during DC1 dives and then gradually ascend to the surface. The profile of DC2 dives is similar to that of a gradual ascent made by gravid loggerhead turtles that was regarded a resting dive because it attained the depth of neutral buoyancy (Minamikawa et al., 1997). Therefore, a DC2 dive may also be a resting dive like a DC1 dive. The reason for terminating the glide during a DC2 dive may be that the duration of a DC1 dive followed by a DC2 dive was significantly longer than it was when followed by other dive types, even though the surface duration between DC1 and DC2 dives was not significantly longer. It is likely that the turtles did not replenish their oxygen reserve before DC2 dives, and thus they terminated in a long gliding dive. Another possible explanation is that the turtles stayed at a suitable temperature to prevent their body temperature from decreasing too much. Maintaining a high body temperature speeds up egg maturation, which allows turtles to initiate nesting earlier in the season and, hence, maximize their reproductive output (Fossette et al., 2012).

A considerable proportion of DC3 dives was spent within $2 \mathrm{~m}$ of the surface. Based on our fine-scale depth recordings, we discovered that the surface swimming ( $<2 \mathrm{~m}$ in depth) documented by Eckert (2002) is actually repeated subsurface dives. In other Cheloniidae species, including the leatherback turtle, repeated subsurface dives $(1-10 \mathrm{~m})$ have been regarded as traveling dives (Hochscheid et al., 1999; Houghton et al., 2002; Reina et al., 2005; Seminoff et al., 2006; Okuyama et al., 2013). Short, repeated dives provide efficient respiration while swimming (Okuyama et al., 2014). Moreover, gliding ascents at shallow depths provides locomotive efficiency by converting positive buoyancy to propulsive force. Turtles have to actively swim only while descending against positive buoyancy. Thus, the repeated DC3 sequence was probably performed to travel with efficient locomotion and respiration.

The DC4 dive was previously documented as an extraordinarily deep dive made during internesting activity and postnesting migration (Eckert et al., 1986, 1989; Houghton et al., 2008). Dives of this type are concentrated in the daytime. It should be noted that the turtles experienced extreme cold temperatures $\left(5.4^{\circ} \mathrm{C}\right.$ at $\left.846 \mathrm{~m}\right)$ in deep water. Although, it may be associated with thermoregulation, alternative explanations for the role of extraordinarily deep dives are various (e.g., predator avoidance, prey detection; Houghton et al., 2008). The duration of DC4 dives seemed to exceed the turtle's ADL. In fact, the mean PDSD of DC4 dives was longer than it was for other types. A couple of PDSDs after DC4 dives were comparatively short, but all of these were followed by a DC3 dive, which further indicates that $\mathrm{DC} 3$ dives may play a role in respiration while swimming.

Other studies grouped subsurface dives into the surface period (Eckert et al., 1989; Eckert, 2002; Southwood et al., 2005; Casey et al., 2010), except for Reina et al. (2005). However, we have demonstrated that surface swimming and surface "stays" were different behaviors. In fact, a surface period without any change in depth or swimming rate was also recorded in Figure 4 of Eckert (2002). Therefore, these two behaviors should be considered distinct. A linear relationship between PDSD and dive duration indicates that the turtles mainly stay at the surface for respiration. The ESPs tended to occur after long dives, often with a few short dives beforehand, which supports the notion that an ESP provides time for the degradation of lactic acid accumulated during preceding dives. Although, the recovery time required by leatherback turtles is unknown, Weddell seals (Leptonychotes weddellii) require approximately $120 \mathrm{~min}$ recovery time per 60 min of dive time (Kooyman et al., 1980). However, comparison of the number ESPs (469) with the number of dives exceeding ADL (42 dives, assuming ADL was $25 \mathrm{~min}$ ) indicates that the turtles may have stayed at the surface for reasons other than recovery. That ESP incidence concentrated in the daytime and took place in succession allows us to speculate that turtles bask to aid immune function, egg development, and to elevate body temperature, as they do in temperate regions (James et al., 2005). In fact, a drastic increment in ambient temperature during the surface period would indicate that the carapace rose to the surface. If these behaviors are associated with head gain, gravid leatherback turtles might thermoregulate to the highest possible temperature as possible until overheating, by shuttling between deep cold waters and warm surface waters. However, Southwood et al. (2005) documented that subcarapace temperature during prolonged surface periods was not significantly higher than it was during routine dives, indicating that the turtles might indeed conduct subsurface swimming or that leatherbacks might have limited capacity for heat gain while basking (Penick, 1996). Another possibility is that the ESP might be associated with foraging behavior, i.e., prey handling, and aid in the digestion of food and recovery from decreases in body temperature associated with gulping (Casey et al., 2010).

\section{Diel Patterns}

DC1 dives were deeper in daytime and shallower at night in our study. This is similar to what has been observed in the Caribbean (Eckert et al., 1986, 1989; Eckert, 2002; Myers and Hays, 2006; Myers et al., 2006). A similar diel pattern was also observed in the U-dives made by turtles in Malaysia and Costa Rica (Eckert et al., 1996; Shillinger et al., 2010). In our study, even at maximum dive depth, the ambient light level in the daytime was higher than it was at the surface in the nighttime. Therefore, the shift in dive depth between day and night may indicate that the depth of the dives associated with resting depends on ambient light conditions under which they can ensure their safety. Why was mean dive depth greatest in early morning (06:00-08:00)? This same trend was recorded in gravid green turtles during the internesting interval (C. mydas; Okuyama, unpublished data). It may be associated with the drastic change in ambient light levels at sunrise.

In the daytime, turtles often performed repeated, shallow, subsurface dives or ESPs. During the nighttime, the proportion of the time spent in DC2 dives increased. Thus, turtles may have increased their activity in the daytime and spent more effort thermoregulating and resting during the nighttime.

\section{Time-Series Shifts during Internesting Interval}

Significant increases in the time spent in DC1 dives the first day of the internesting interval indicates that the turtles stayed in deep 
waters longer, although significant changes in maximum dive depth were not observed in archival, SRDL, or TAD data. The gravid turtles might have made longer DC1 dives to cool down after nesting, when their body temperatures elevate as a result of crawling and nesting activities on the beach. A steady decline in the gastrointestinal tract temperature was observed after leaving the beach in previous studies (Southwood et al., 2005; Casey et al., 2010).

A few other studies have indicated significant changes in leatherback diving behavior toward the end of the internesting interval, such as a decrease in dive effort and an increase in dive variability in French Guiana (Fossette et al., 2007) and shallower dives in Costa Rica (Southwood et al., 1999, 2005). In our study, however, no apparent shift in dive depth was observed throughout the internesting interval, and the turtles performed deep dives a few hours before nesting events. This could be because of the bathymetries of waters adjacent to nesting beaches in Papua Barat and Solomon Islands, which exhibit sudden dropoffs to $>1000 \mathrm{~m}$ in depth, so dive behavior is not restricted when turtles approach the nesting beach. On only one occasion did we observe a consistent diel pattern, with residence in shallow water during the nighttime for 2 days before nesting, that could have indicated a search for an appropriate nesting place.

\section{Behavioral Strategies of Gravid Leatherback Turtles during the Internesting Interval}

Fine-scale dive data showed that gravid leatherback turtles nesting in both Papua Barat and Solomon Islands routinely dived to deep waters, presumably with gliding, and spent a considerable amount of time in cold waters below the thermocline. In these two regions the nesting season was different, but the water temperature was almost the same. Therefore, this dive pattern may indicate that gravid leatherback turtles nesting in both Papua Barat and Solomon Islands allocate their internesting interval mainly to resting and cooling-down. This idea may be true of nesting turtles in St. Croix and Grenada, that exhibit the same pattern of routine deep dives (Eckert et al., 1989; Myers and Hays, 2006), although feed opportunistically (Casey et al., 2010). Another dive pattern characterized by U-dives that has been observed in Malaysia (Eckert et al., 1996) and Costa Rica (Southwood et al., 1999, 2005; Reina et al., 2005; Wallace et al., 2005; Shillinger et al., 2010) has also been interpreted as resting behavior. Only in French Guiana (Fossette et al., 2007) do gravid leatherbacks continuously swim in shallow waters during the internesting interval, however, these turtles does not seem to feed during the nesting season (Plot et al., 2013). In short, gravid leatherback turtles in all regions except for French Guiana seem to be capital breeders that do not change their behavioral strategy with geography. They use an energy-saving strategy during most of the internesting intervals that involves gliding to or resting on the sea floor where the water is colder. Their behavioral tactics (i.e., dive patterns), on the other hand, did appear to vary in response to bathymetric constraints. Leatherbacks in French Guiana might conserve their energy while ascending from repeated shallow dives (mean depth: $9.4 \mathrm{~m}$; Fossette et al.,
2007), during which they are assumed to have positive buoyancy (Fossette et al., 2010).

Subsurface swimming and ESPs in the daytime are characteristic behaviors in gravid leatherback turtles, particularly for turtles performing routine deep dives (Eckert, 2002; Southwood et al., 2005; this study). The functions of these behaviors remain unclear. Elucidating the function of the ESP, as well as the extraordinarily deep dive (DC4), is important for understating the behavioral strategies of gravid leatherback turtles during the internesting interval.

Rapid, behaviorally-mediated responses to changing thermal environments have important implications for understanding population responses to climate change (Kealoha-Freidenburg and Skelly, 2004). Global warming would force gravid leatherback turtles in tropical regions to spend more time in cold, deep waters to prevent overheating, which might increase travel costs and, consequently, reduce reproductive output.

\section{AUTHOR CONTRIBUTIONS}

$\mathrm{SB}, \mathrm{PD}$ conducted the field work and collected the data; JO, JS, PD, and SB conceived the study and planned the analysis approach; JO analyzed the dive data and took the lead writing the manuscript; JO, JS, $\mathrm{PD}$, and SB interpreted the results, contributed to writing and revising the manuscript.

\section{ACKNOWLEDGMENTS}

We acknowledge the assistance of beach patrollers in the Solomon Islands, and Papua Barat, Indonesia for their participation in the tagging activities presented in this study. The authors thank the World Wildlife Fund (WWF) for Nature-Indonesia (in memoriam: Creusa Hitipeuw), the Papua Barat-Indonesia Forestry Department (BBKSDA), The State University of Papua-Marine Science Department, The Nature Conservancy-Pacific Islands, the Tetepare Descendants' Association, and the communities of Saubeba and Wau for logistical support at the nesting beaches. The Indonesian Institute of Sciences (LIPI), and the Solomon Islands Department of Environment and Conservation provided research permits for telemetry deployments. Financial support and personnel were provided by the National Marine Fisheries Service (Southwest Fisheries Science Center, Southwest Region, Pacific Islands Region, and Office of Protected Resources). We also thank the Tagging of Pacific Predators (TOPP) program of the Census of Marine Life, for providing some of the transmitters used in this study. This study was also supported by JSPS Postdoctoral Fellowships for Research Abroad (JO 24-473). The authors wish to acknowledge use of the Maptool program of SEATURTLE. ORG for maps in this paper.

\section{SUPPLEMENTARY MATERIAL}

The Supplementary Material for this article can be found online at: http://journal.frontiersin.org/article/10.3389/fmars. 2016.00166 


\section{REFERENCES}

Benson, S. R., Eguchi, T., Foley, D. G., Forney, K. A., Bailey, H., Hitipeuw, C., et al. (2011). Large-scale movements and high-use areas of western pacific leatherback turtles, Dermochelys coriacea. Ecosphere 2:84. doi: 10.1890/ES1100053.1

Bonfil, R., Meÿer, M., Scholl, M. C., Johnson, R., O’Brien, S., Oosthuizen, H., et al. (2005). Transoceanic migration, spatial dynamics, and population linkages of white sharks. Science 310, 100-103. doi: 10.1126/science.1114898

Bonnet, X., Bradshaw, D., and Shine, R. (1998). Capital versus income breeding: an ectothermic perspective. Oikos 83, 333-342. doi: 10.2307/3546846

Bostrom, B. L., Jones, T. T., Hastings, M., and Jones, D. R. (2010). Behaviour and physiology: the thermal strategy of leatherback turtles. PLoS ONE 5:e13925. doi: 10.1371/journal.pone.0013925

Casey, J., Garner, J., Garner, S., and Williard, A. S. (2010). Diel foraging behavior of gravid leatherback sea turtles in deep waters of the Caribbean Sea. J. Exp. Biol.. 213, 3961-3971. doi: 10.1242/jeb.048611

Cochran, W. G. (1954). Some methods for strengthening the common $\mathrm{x}^{2}$ tests. Biometrics 10, 417-451. doi: 10.2307/3001616

Dill, L. M. (1987). Animal decision making and its ecological consequences: the future of aquatic ecology and behaviour. Can. J. Zool. 65, 803-811. doi: $10.1139 / \mathrm{z} 87-128$

Drent, R. H., and Daan, S. (1980). The prudent parent: energetic adjustments in avian breeding. Ardea 68, 225-252.

Eckert, S. A. (2002). Swim speed and movement patterns of gravid leatherback sea turtles (Dermochelys coriacea) at St Croix, US Virgin Islands. J. Exp. Biol. 205, 3689-3697.

Eckert, S. A., Eckert, K. L., Ponganis, P., and Kooyman, G. L. (1989). Diving and foraging behavior of leatherback sea turtles (Dermochelys coriacea). Can. J. Zool. 67, 2834-2840. doi: 10.1139/z89-399

Eckert, S. A., Liew, H. C., Eckert, K. L., and Chan, E. H. (1996). Shallow water diving by leatherback turtles in the South China Sea. Chel. Cons. Biol. 2, 237-243.

Eckert, S. A., Nellis, D. W., Eckert, K. L., and Kooyman, G. L. (1986). Diving patterns of two leatherback sea turtles (Dermochelys coriacea) during internesting intervals at Sandy Point, St. Croix, U.S. Virgin Islands. Herpetologica 42, 381-388.

Fossette, S., Corbel, H., Gaspar, P., Le Maho, Y., and Georges, J.-Y. (2008a). An alternative technique for the long-term satellite tracking of leatherback turtles. Endang. Species Res. 4, 33-41. doi: 10.3354/esr00039

Fossette, S., Ferraroli, S., Tanaka, H., Ropert-Coudert, Y., Arai, N., Sato, K., et al. (2007). Dispersal and dive patterns in gravid leatherback turtles during the nesting season in French Guiana. Mar. Ecol. Prog. Ser. 338, 233-247. doi: $10.3354 /$ meps338233

Fossette, S., Gaspar, P., Handrich, Y., Le Maho, Y., and Georges, J. Y. (2008b). Dive and beak movement patterns in leatherback turtles Dermochelys coriacea during internesting intervals in French Guiana. J. Anim. Ecol. 77, 236-246. doi: 10.1111/j.1365-2656.2007.01344.x

Fossette, S., Gleiss, A. C., Myers, A. E., Garner, S., Liebsch, N., Whitney, N. M., et al. (2010). Behaviour and buoyancy regulation in the deepest-diving reptile: the leatherback turtle. J. Exp. Biol. 213, 4074-4083. doi: 10.1242/jeb.048207

Fossette, S., Schofield, G., Lilley, M. K. S., Gleiss, A. C., and Hays, G. C. (2012). Acceleration data reveal the energy management strategy of a marine ectotherm during reproduction. Func. Ecol. 26, 324-333. doi: 10.1111/j.13652435.2011.01960.x

Hall, M., Frank, E., Holmes, G., Pfahringer, B., Reutemann, P., and Witten, I. H. (2009). The WEKA data mining software: an update. SIGKDD Explor. Newsl. 11, 10-18. doi: 10.1145/1656274.1656278

Hays, G. C., Glen, F., Broderick, A. C., Godley, B. J., and Metcalfe, J. D. (2002). Behavioural plasticity in a large marine herbivore: contrasting patterns of depth utilisation between two green turtle (Chelonia mydas) populations. Mar. Biol. 141, 985-990. doi: 10.1007/s00227-002-0885-7

Hays, G. C., Houghton, J. D. R., Isaacs, C., King, R. S., Lloyd, C., and Lovell, P. (2004). First records of oceanic dive profiles for leatherback turtles, Dermochelys coriacea, indicate behavioural plasticity associated with long-distance migration. Anim. Behav. 67, 733-743. doi: 10.1016/j.anbehav.2003.08.011
Hitipeuw, C., Dutton, P. H., Benson, S. R., Thebu, J., and Bakarbessy, J. (2007). Population status and internesting movement of leatherback turtles, Dermochelys coriacea, nesting on the northwest coast of Papua, Indonesia. Chel. Cons. Biol. 6, 28-36. doi: 10.2744/1071-8443(2007)6[28:PSAIMO]2.0.CO;2

Hochscheid, S., Godley, B. J., Broderick, A. C., and Wilson, R. P. (1999). Reptilian diving: highly variable dive patterns in the green turtle Chelonia mydas. Mar. Ecol. Prog. Ser. 185, 101-112. doi: 10.3354/meps 185101

Houghton, J. D., Doyle, T. K., Davenport, J., Wilson, R. P., and Hays, G. C. (2008) The role of infrequent and extraordinary deep dives in leatherback turtles (Dermochelys coriacea). J. Exp. Biol. 211, 2566-2575. doi: 10.1242/jeb.020065

Houghton, J. D. R., Broderick, A. C., Godley, B. J., Metcalfe, J. D., and Hays, G. C. (2002). Diving behaviour during the internesting interval for loggerhead turtles Caretta caretta nesting in Cyprus. Mar. Ecol. Prog. Ser. 227, 63-70. doi: 10.3354/meps227063

James, M. C., Myers, R. A., and Ottensmeyer, C. A. (2005). Behaviour of leatherback sea turtles, Dermochelys coriacea, during the migratory cycle. Proc. Biol. Sci. B 272, 1547-1555. doi: 10.1098/rspb.2005.3110

Kealoha-Freidenburg, L., and Skelly, D. K. (2004). Microgeographical variation in thermal preference by an amphibian. Ecol. Lett. 7, 369-373. doi: 10.1111/j.14610248.2004.00587.x

Keinath, J. A., and Musick, J. A. (1993). Movements and diving behavior of a leatherback turtle, Dermochelys coriacea. Copeia 1993, 1010-1017. doi: $10.2307 / 1447078$

Kooyman, G. L., Wahrenbrock, E. A., Castellini, R. W., Davis, R. W., and Sinnett, E. E. (1980). Aerobic and anaerobic metabolism during voluntary diving in Weddell seals: evidence of preferred pathways from blood chemistry and behavior. J. Comp. Physiol. 138, 335-346. doi: 10.1007/BF006 91568

Kramer, D. L. (1988). The behavioural ecology of air breathing by aquatic animals. Can. J. Zool. 66, 89-94. doi: 10.1139/z88-012

Lourdais, O., Bonnet, X., Shine, R., DeNardo, D., Naulleau, G., and Guillon, M. (2002). Capital-breeding and reproductive effort in a variable environment: a longitudinal study of a viviparous snake. J. Anim. Ecol. 71, 470-479. doi: 10.1046/j.1365-2656.2002.00612.x

McMahon, C. R., Autret, E., Houghton, J. D. R., Lovell, P., Myers, A. E., and Hays, G. C. (2005). Animal-borne sensors successfully capture the real-time thermal properties of ocean basins. Limnol. Oceanog. Methods. 3, 392-298. doi: 10.4319/lom.2005.3.392

Miller, J. D. (1997). "Reproductioni n sea turtles," in The Biology of Sea Turtles, eds P. L. Lutz and J. A. Musick (Boca Raton, FL: CRC Press), 51-80.

Miller, P. J. O. M., Shapiro, A. D., and Deecke, V. B. (2010). The diving behaviour of mammal-eating killer whales (Orcinus orca): variations with ecological not physiological factors. Can. J. Zool. 88, 1103-1112. doi: 10.1139/Z10-080

Minamikawa, S., Naito, Y., and Uchida, I. (1997). Buoyancy control in diving behavior of the loggerhead turtle, Caretta caretta. J. Ethol. 15, 109-118. doi: 10.1007/BF02769396

Myers, A. E., and Hays, G. C. (2006). Do leatherback turtles Dermochelys coriacea forage during the breeding season? A combination of data-logging devices provide new insights. Mar. Ecol. Prog. Ser. 322, 259-267. doi: 10.3354/meps322259

Myers, A. E., Lovell, P., and Hays, G. C. (2006). Tools for studying animal behaviour: validation of dive profiles relayed by the Argos satellite system. Anim. Behav. 71, 989-993. doi: 10.1016/j.anbehav.2005.06.016

Okuyama, J., Nakajima, K., Noda, T., Kimura, S., Kamihata, H., Kobayashi, M., et al. (2013). Ethogram of immature green turtles: behavioral strategies for somatic growth in large marine herbivores. PLoS ONE 8:e65783. doi: 10.1371/journal.pone.0065783

Okuyama, J., Tabata, R., Nakajima, K., Arai, N., Kobayashi, M., and Kagawa, S. (2014). Surfacers change their dive tactics depending on the aim of the dive: evidence from simultaneous measurements of breaths and energy expenditure. Proc. Roy. Soc. B 281:20140040. doi: 10.1098/rspb.2014.0040

Paladino, F. V., O'Connor, M. P., and Spotila, J. R. (1990). Metabolism of leatherback turtles, gigantothermy, and thermoregulation of dinosaurs. Nature 344, 858-860. doi: 10.1038/344858a0

Penick, D. N. (1996). Thermoregulatory Physiology of Leatherback (Dermochelys coriacea) and Green Sea Turtles (Chelonia mydas). Ph.D. dissertation, Drexel University, Philadelphia, PA. 
Pittman, R. L., and Dutton, P. H. (2004). Killer whale predation on a leatherback turtle in the Northeast Pacific. Pac. Sci. 58, 497-498. doi: 10.1353/psc.2004.0034

Plot, V., Jenkins, T., Robin, J.-P., Fossette, S., and Georges, J.-Y. (2013). Leatherback turtles are capital breeders: morphometric and physiological evidence from longitudinal monitoring. Physiol. Biochem. Zool. 86, 385-397. doi: $10.1086 / 671127$

Quinlan, J. R. (1993). C4.5: Programs for Machine Learning, Vol. 312. San Mateo, CA: Morgan Kaufmann Publishers.

Reina, R. D., Abernathy, K. J., Marshall, G. J., and Spotila, J. R. (2005). Respiratory frequency, dive behaviour and social interactions of leatherback turtles, Dermochelys coriacea during the inter-nesting interval. J. Exp. Mar. Biol. Ecol. 316, 1-16. doi: 10.1016/j.jembe.2004.10.002

Santos, A. J. B., Freire, E. M. X., Bellini, C., and Corso, G. (2010). Body mass and the energy budget of gravid hawksbill turtles (Eretmochelys imbricata) during the nesting season. J. Herpetol. 44, 352-359. doi: 10.1670/08-287.1

Sato, K. (2014). Body temperature stability achieved by the large body mass of sea turtles. J. Exp. Biol. 217, 3607-3614. doi: 10.1242/jeb.109470

Schofield, G., Pantis, J. D., and Hays, G. C. (2006). Behaviour analysis of the loggerhead sea turtle Caretta caretta from direct in-water observation. Endang. Species Res. 2, 71-79. doi: 10.3354/esr002071

Seigel, R. A., and Fitch, H. S. (1985). Annual variation in reproduction in snakes in a fluctuating environment. J. Anim. Ecol. 54, 497-505. doi: 10.2307/4494

Seminoff, J. A., Jones, T., and Marshall, G. J. (2006). Underwater behaviour of green turtles monitored with video-time-depth recorders: what's missing from dive profiles? Mar. Ecol. Progr. Ser. 322, 269-280. doi: 10.3354/meps322269

Shillinger, G. L., Swithenbank, A. M., Bograd, S. J., Bailey, H., Castelton, M. R., Wallace, B. P., et al. (2010). Identification of high-use internesting habitats for eastern Pacific leatherback turtles: role of the environment and implications for conservation. Endang. Species Res. 10, 215-232. doi: 10.3354/esr00251
Southwood, A. L., Andrews, R. D., Lutcavage, M. E., Paladino, F. V., West, N. H., George, R. H., et al. (1999). Heart rates and diving behavior of leatherback sea turtles in the eastern Pacific Ocean. J Exp Biol 202, 1115-1125.

Southwood, A. L., Andrews, R. D., Paladino, F. V., and Jones, D. R. (2005). Effects of diving and swimming behavior on body temperatures of Pacific leatherback turtles. Physiol. Biochem. Zool. 78, 285-297. doi: 10.1086/427048

Southwood, A. L., Reina, R. D., Jones, V. S., and Jones, D. R. (2003). Seasonal diving patterns and body temperatures of juvenile green turtles at Heron Island, Australia. Can. J. Zool. 81, 1014-1024. doi: 10.1139/z03-081

Wallace, B. P., Sotherland, P. R., Tomillo, P. S., Reina, R. D., Spotila, J. R., and Paladino, F. V. (2007). Maternal investment in reproduction and its consequences in leatherback turtles. Oecologia 152, 37-47. doi: 10.1007/s00442006-0641-7

Wallace, B. P., Williams, C. L., Paladino, F. V., Morreale, S. J., Lindstrom, R. T., and Spotila, J. R. (2005). Bioenergetics and diving activity of internesting leatherback turtles Dermochelys coriacea at Parque Nacional Marino Las Baulas, Costa Rica. J. Exp. Biol. 208, 3873-3884. doi: 10.1242/jeb. 01860

Conflict of Interest Statement: The authors declare that the research was conducted in the absence of any commercial or financial relationships that could be construed as a potential conflict of interest.

Copyright () 2016 Okuyama, Seminoff, Dutton and Benson. This is an open-access article distributed under the terms of the Creative Commons Attribution License (CC $B Y)$. The use, distribution or reproduction in other forums is permitted, provided the original author(s) or licensor are credited and that the original publication in this journal is cited, in accordance with accepted academic practice. No use, distribution or reproduction is permitted which does not comply with these terms. 